\title{
Nutrient intakes and cognitive function in older adults: a longitudinal study of the Aberdeen 1936 Birth Cohort
}

\author{
X. Jia ${ }^{1}$, L. S. Aucott ${ }^{2}$, H. Fox ${ }^{2}$, L. J. Whalley ${ }^{2}$ and G. McNeill ${ }^{2}$ \\ ${ }^{1}$ Health Services Research Unit and ${ }^{2}$ Population Health Section, University of Aberdeen, Foresterhill, \\ Aberdeen AB25 2ZD, UK
}

Cognitive function declines noticeably from the age of about 50 years. Here, we investigate relationships between nutrient intakes at the age of about 68 years with (i) cognitive function at the age of 68 years and (ii) cognitive changes from the age of 64 years to 68 years.

We recruited a cohort of volunteers all born in 1936 who were living independently in Aberdeen and whose childhood IQ had been assessed at age 11 years as part of the Scottish Mental Survey 1947. Participants ( $n$ 480) were recruited in 1999-2001. At about ages 64, 66 and 68 years, six cognitive tests (of non-verbal reasoning, verbal memory, information processing speed, verbal ability, construction ability and executive function) were administered ${ }^{(1)}$. Global cognitive function was estimated using principal component analysis of the scores of the five cognitive tests. At age 68 years, 298 participants self-completed a validated 175 -item FFQ ${ }^{(2)}$ of whom 269 completed the FFQ in acceptable quality. Intakes of ten nutrients (from food and supplements) were derived from the FFQ. Associations between each energy-adjusted nutrient intake with each aspect of cognitive function were modelled using general linear regression. Nutrient intakes with and without dietary supplements were studied separately.

Association of nutrient intakes (from food and food supplements) and cognitive function at the age of 68 years: standardised regression coefficients from general linear model.

\begin{tabular}{|c|c|c|c|c|c|c|c|}
\hline Nutrients & $\begin{array}{c}\text { Non-verbal } \\
\text { reasoning } \\
(n \text { 222) }\end{array}$ & $\begin{array}{l}\text { Verbal } \\
\text { memory } \\
(n 215)\end{array}$ & $\begin{array}{c}\text { Information } \\
\text { processing } \\
\text { speed }\left(\begin{array}{l}n \\
218\end{array}\right)\end{array}$ & $\begin{array}{c}\text { Verbal } \\
\text { ability } \\
(n \text { 224) }\end{array}$ & $\begin{array}{c}\text { Constructional } \\
\text { ability } \\
(n=217)\end{array}$ & $\begin{array}{l}\text { Executive } \\
\text { function } \\
(n \text { 218) }\end{array}$ & $\begin{array}{c}\text { Global } \\
\text { function } \\
(n=206)\end{array}$ \\
\hline Thiamin & -0.05 & 0.01 & -0.06 & 0.03 & 0.07 & 0.04 & 0.08 \\
\hline Riboflavin & -0.04 & 0.002 & 0.12 & 0.07 & 0.09 & 0.06 & 0.06 \\
\hline Vitamin $\mathrm{B}_{6}$ & -0.07 & 0.03 & 0.09 & 0.04 & 0.04 & 0.06 & 0.08 \\
\hline Vitamin $\mathrm{B}_{12}$ & $-0.12 *$ & 0.03 & 0.04 & 0.04 & -0.02 & -0.09 & -0.03 \\
\hline Folate & -0.04 & 0.04 & 0.05 & $0.12 * *$ & 0.11 & 0.10 & 0.10 \\
\hline Retinol & 0.03 & 0.01 & -0.02 & 0.05 & 0.10 & 0.07 & 0.06 \\
\hline$\beta$-carotene & 0.02 & 0.001 & 0.06 & -0.07 & 0.06 & 0.07 & 0.03 \\
\hline Vitamin C & -0.05 & 0.01 & 0.03 & 0.03 & -0.02 & 0.02 & 0.01 \\
\hline Vitamin E & 0.02 & 0.03 & 0.03 & 0.06 & -0.01 & 0.11 & 0.06 \\
\hline $\mathrm{Zn}$ & -0.02 & $0.17 * *$ & 0.04 & 0.06 & 0.05 & 0.11 & 0.09 \\
\hline
\end{tabular}

After adjustment for age, sex, childhood IQ, smoking, social economic status and years of full-tem education, higher vitamin $\mathrm{B}_{12}$ intake was associated with worse non-verbal reasoning at the age of 68 years $(P<0.05)$ and higher folate intake was associated with better verbal ability at the age of 68 years $(P<0.01)$. Higher $\mathrm{Zn}$ intake was associated with both better verbal memory at the age of 68 years $(P<0.01)$ and less decline in memory from the age of 64 years to 68 years $(P<0.001)$ (data not shown). For all significant associations, the proportions of the variance explained by nutrient intake in the fully adjusted models ranged from $0.6 \%$ to $2 \%$. Similar patterns were seen for nutrient intakes from food alone.

The results suggest that there was no single nutrient significantly associated with all aspects of cognitive function and/or changes studied.

1. Whalley LJ, Fox HC, Starr JM et al. (2004) Age at natural menopause and cognition. Maturitas 49, 148-156.

2. Jia X, McNeill GM, Craig LCA et al. (2008) Repeatability and validity of a food frequency questionnaire in free-living old people and the relation with cognition. J Nutr Health Aging 12, 735-741. 